This item was submitted to Loughborough's Research Repository by the author.

Items in Figshare are protected by copyright, with all rights reserved, unless otherwise indicated.

\title{
Effects of acute postexercise chocolate milk consumption during intensive judo training on the recovery of salivary hormones, salivary SIgA, mood state, muscle soreness, and judo-related performance
}

\section{PLEASE CITE THE PUBLISHED VERSION}

http://www.nrcresearchpress.com/journal/apnm

\section{PUBLISHER}

NRC Research Press / (C) The Authors

\section{VERSION}

AM (Accepted Manuscript)

\section{PUBLISHER STATEMENT}

This work is made available according to the conditions of the Creative Commons Attribution-NonCommercialNoDerivatives 4.0 International (CC BY-NC-ND 4.0) licence. Full details of this licence are available at: https://creativecommons.org/licenses/by-nc-nd/4.0/

\section{LICENCE}

CC BY-NC-ND 4.0

\section{REPOSITORY RECORD}

Papacosta, Elena, George P. Nassis, and Michael Gleeson. 2019. "Effects of Acute Postexercise Chocolate Milk Consumption During Intensive Judo Training on the Recovery of Salivary Hormones, Salivary Siga, Mood State, Muscle Soreness, and Judo-related Performance". figshare. https://hdl.handle.net/2134/20926. 
Title:

2 Effects of acute post-exercise chocolate milk consumption during intensive judo training on the 3 recovery of salivary hormones, salivary $\operatorname{IgA}$, mood state, muscle soreness and judo-related 4 performance.

5

6 Authors:

7 Elena Papacosta-Kokkinou, George Nassis and Michael Gleeson

8

9 Corresponding author:

10 Elena Papacosta-Kokkinou, 5 Myronos street, Limassol, Cyprus, telephone number: 00357

11 25250611, email: elenapapacosta@ hotmail.com.

12

13 Affiliations:

14 Elena Papacosta-Kokkinou: School of Sport, Exercise and Health Sciences, Loughborough

15 University, Loughborough, United Kingdom, email elenapapacosta@ hotmail.com;

16 George Nassis: National Sports Medicine Programme-Excellence in Football Project, Sports

17 Medicine and Orthopaedic Hospital, Aspetar, Doha, Qatar, georgenassis@gmail.com

18 Michael Gleeson: School of Sport, Exercise and Health Sciences, Loughborough University, 19 Loughborough, United Kingdom, email m.gleeson@lboro.ac.uk.

20 
23 This study examined the effects of post-exercise chocolate milk (CM) or water (W) consumption

24 during 5 days of intensive judo training with concomitant weight loss on salivary cortisol and testosterone, salivary secretory immunoglobulin A (SIgA), delayed-onset muscle soreness (DOMS) and judo-related performance. Twelve trained male judo athletes engaged in 5 days of intensive judo training followed by a simulated judo competition, on two separate training weeks interspersed by 14 days. Immediately post-training, the athletes consumed $1000 \mathrm{ml}$ of $\mathrm{W}$ on week 1 and the equivalent volume of CM on week 2. During both weeks, athletes were instructed to "make weight" for the upcoming competition. Judo-related performance in the timed-push-ups and the Special Judo Fitness Test improved by $14.6 \%$ and $6.8 \%$, respectively, at the end of the

32 training week with CM consumption (both $\mathrm{p}<0.001)$. Decreased salivary cortisol $(\mathrm{p}<0.01)$ and a 33 trend for increased salivary testosterone/cortisol ratio $(\mathrm{p}=0.07)$ were also observed mid-week in 34 the CM condition. Saliva flow rate was higher during the week with CM intake compared with $\mathrm{W}(\mathrm{p}<0.001)$. DOMS $(\mathrm{p}<0.001)$ and mood disturbance $(\mathrm{p}<0.0001)$ increased after the first day of 36 training in the $\mathrm{W}$ but not in the $\mathrm{CM}$ condition. Responses of salivary testosterone and SIgA were

37 similar between drinks ( $\mathrm{p}>0.05)$. Body mass decreased by $1.9 \%$ in the $\mathrm{W}$ condition and by $1.1 \%$ 38 in the CM condition, with no significant differences between drinks. This study indicates that 39 post-exercise $\mathrm{CM}$ consumption during short-term intensive judo training is beneficial for 40 enhancing aspects of recovery, without affecting intentional weight loss.

42 Keywords: carbohydrate-protein beverage, making weight, salivary cortisol, salivary testosterone, mucosal immunity, special judo fitness test 


\section{Introduction}

46 Chocolate milk contains carbohydrates $(\mathrm{CHO})$ and protein, in addition to fluid and electrolytes

47 and could potentially serve as a post-exercise recovery drink. Studies show that chocolate milk

48 (CM) consumption after exercise can enhance subsequent endurance performance during

49 repeated bouts of exercise (Karp et al. 2006; Thomas et al. 2009; Ferguson-Stegall et al. 2011;

50 Spaccarotella and Andzel 2011; Lunn et al. 2012) and speed up recovery during intensive soccer

51 training (Gilson et al. 2010; Spaccarotella and Andzel 2011). In addition, post-exercise

52 consumption of whole milk has been shown to be beneficial in restoring sweat losses in

53 dehydrated subjects (Shirreffs et al. 2007; Watson et al. 2008). Dairy proteins found in fluid milk

54 have been reported to elicit acute rises in muscle protein synthesis following endurance

55 (Ferguson-Stegall et al. 2011) and resistance exercise (Wilkinson et al. 2007) and could

56 potentially be effective in attenuating markers of exercise-induced muscle damage (Cockburn et

57 al. 2008; Pritchett et al. 2009; Gilson et al. 2010) and delayed onset muscle soreness (DOMS)

58 (Cockburn et al. 2010). Attenuated ratings of DOMS and serum creatine kinase (CK) responses

59 were reported when CM was consumed immediately after muscle-damaging exercise (Cockburn

60 et al. 2010); however, other studies report no change in DOMS despite attenuated increases in

61 circulating CK responses during recovery (Cockburn et al. 2008; Pritchett et al. 2009; Gilson et

62 al. 2010). During a brief period of intensified soccer training period, Gilson et al. (2010) reported

63 that post-exercise $\mathrm{CM}$ consumption compared with a $\mathrm{CHO}$-replacement beverage attenuated

64 serum CK responses, despite similar changes between drinks on exercise performance, serum

65 myoglobin concentrations, DOMS and muscle function. Mucosal immunity appears to

66 deteriorate during periods of intensive training (Walsh et al. 2011); however, the effects of post- 
67 exercise $\mathrm{CM}$ consumption during intensive training on saliva secretory immunoglobulin A 68 (SIgA) responses have not been investigated.

69 Judo is a sport with weight categories, where athletes often engage in periods of weight loss in

70 the days preceding a competition. Most usual practices involve rapid weight loss ( $>5$ days)

71 procedures, mainly by food and fluid restriction. Several unorthodox and aggressive rapid weight

72 loss methods are followed by judo athletes, such as intensive exercising, skipping meals and

73 limiting $\mathrm{CHO}$ intake, restricting fluid intake and positively promoting sweat losses which can

74 have detrimental effects on their competition performance and health (Artioli et al. 2010). The

75 combination of rapid weight loss practices and intense exercise training in the week preceding

76 the competition could have adverse effects on athletes' competition performance.

77 The majority of investigations that have assessed the effects of CM included endurance-type

78 sports and examined aspects of laboratory-based endurance performance and muscle function

79 tests. Therefore, the purpose of this study was to examine whether post-exercise CM

80 consumption during 5 days of intense judo training can enhance aspects of recovery, by limiting

81 the disturbances in salivary hormones, mucosal immunity and mood state, attenuating muscle

82 soreness and improving subsequent judo-specific performance, without affecting intentional

83 weight loss.

84

85 Materials and Methods

86

87 Participants 
88 Twelve trained, male, national level judo athletes volunteered to participate in the study (mean \pm

89 SD: age $19 \pm 4$ years; height $175 \pm 7 \mathrm{~cm}$; body mass $77.4 \pm 7.9 \mathrm{~kg}$; body fat $11.1 \pm 4.2 \%$;

90 maximal oxygen uptake $56.8 \pm 3.2 \mathrm{ml} \cdot \mathrm{kg}^{-1} \cdot \mathrm{min}^{-1}$; training experience $7 \pm 3$ years.). All athletes

91 had competed in judo for at least five years and trained a minimum of 4 times per week. Subjects

92 were lactose tolerant, non-smokers, not taking any form of medication, refrained from alcohol

93 consumption and remained free from illness for the total duration of the study. No overt signs of

94 overreaching (as described by Meeusen et al. 2013) were observed in the subjects before

95 commencing the study; thus subjects in the weeks preceding the study did not present any

96 deterioration in performance, disturbances in mood, reported no recent illness (upper respiratory

97 symptoms) and were generally in good form physically and psychologically. Prior to the study,

98 all subjects completed an informed consent and a health screening questionnaire. The national

99 ethics committee approved all procedures undertaken. For the athletes under 18 years old (17

100 years at the time of study) informed consent was given by their guardians (Cyprus National 101 Bioethics Committee).

103 Procedures

104 Design

105 This was a field study that took place in January during pre-season preparations. In week 1, 106 athletes initially engaged in 5 days of intensive judo training (days 1-5, Mon-Fri) followed by a 107 simulated competition (day 6, Sat), whereas the athletes consumed $1000 \mathrm{ml}$ of $\mathrm{W}$ immediately 108 post-exercise. Following a period of 14 days, the same procedures were repeated; in week 2, the 109 same athletes engaged in 5 days of intensive judo training (days 1-5, Mon-Fri) followed by a 
110 simulated competition (day 6, Sat), whereas the athletes consumed $1000 \mathrm{ml}$ of CM immediately

111 post-exercise (Figure 1). During both weeks, athletes were instructed to "make weight" as to

112 reach the body mass required to compete within their weight category during the simulated

113 competition at the end of each week. The first week served as the observation week to obtain

114 baseline measurements and the second week as the intervention. The simulated competition was

115 organised by the National Judo Federation and, to try to be as close to real-time sporting 116 scenarios, it was organised as to motivate athletes' weight loss and assess any effect of the drink

117 on the changes in body mass. Athletes' body mass ranged 55-90 kg, therefore the amount of CM

118 provided at least $1 \mathrm{~g}$ CHO per $\mathrm{kg}$ body mass (for ingredients see Table 1). Training was

119 performed indoors (dojo) in the evening and consisted of judo-specific skills and drills and mat

120 work. Athletes trained together in the same dojo, under the supervision of the same coach. The

121 training program followed in this study was based on previous weeks, whilst increasing the

122 training load. Athletes engaged in their usual, previous volume of training during the 14-day

123 washout period. Performance tests, questionnaires to assess DOMS and mood state and morning

124 resting saliva samples to assess salivary hormones, salivary SIgA and saliva flow rate were

125 collected frequently throughout the study. Subjects have had their last meals at least $3 \mathrm{~h}$ prior to

126 testing and were instructed to avoid beverages with caffeine and high-CHO content at least $3 \mathrm{~h}$

127 before testing. Subjects were also instructed to avoid milk-based beverages during the duration

128 of the study. Subjects did not train or exercise for 2 days before and after each training week. 


\section{Training quantification}

134 On both training weeks the judo training sessions lasted $2.0-2.5 \mathrm{~h}$ (18:00-20:30 hrs). The 135 training consisted of a warm-up ( 20 min), judo-specific skills and drills and mat work ( 50 136 min), several sets of ground Randori ( 40 min) and standing Randori ( 40 min) and cool-down 137 ( 10 min). Specific judo exercises were identical on both training weeks. To quantify exercise 138 intensity, each subject wore a Polar heart rate (HR) monitor (Polar Electro Oy, Kempele, 139 Finland) during all training sessions. Records of HR for both training sessions were then

140 downloaded to a computer using Polar Team System and \%HRmax, average HR and time spent 141 in each training zone were then individually calculated based on each subject's HRmax. 142 Furthermore, RPE using Borg's 6-20 scale (Borg, 1982) were recorded 30 min following each 143 training session. The training volume was calculated by multiplying the time spent in each 144 training zone by heart rate as a percentage of HRmax (time $\mathrm{x} \%$ HRmax). Training load was 145 calculated as suggested by Foster et al. (2001) by multiplying session RPE by session duration.

147 Dietary control

148 In week 1, the athletes consumed $1000 \mathrm{ml}$ of $\mathrm{W}$, whereas in week 2 they consumed $1000 \mathrm{ml}$ of 149 CM during post-exercise recovery. Both drinks were given within 10 min post-training and were 150 consumed within $1 \mathrm{~h}$ of recovery. Subjects were instructed not to consume any other drinks or 151 foods other than their prescribed beverage for $1.5 \mathrm{~h}$ post-training. For the needs of simulated 152 competition, subjects were asked to "make weight" for the upcoming simulated competition 153 following their usual nutritional practices during the first week; they were instructed to replicate 
154 the same weight loss practices on the following week. On week 1, the athletes completed a 155 personalised food diary with the type, amount and timing of foods and drinks they consumed.

156 Food diaries were given back to the athletes on week 2 and they were instructed to replicate the 157 same dietary habits. Subjects were instructed to stay as close to the first treatment period 158 regarding the amount, type and timing of food and drinks they consumed. Athletes would 159 decrease their body mass until they reached the body weight required for their weight category; 160 this would suggest decreasing their body weight by $1.5-2.0 \%$ on both weeks. Days 1,3 and 5 161 had been chosen for body mass assessments as to examine the differences of $\mathrm{CM}$ or $\mathrm{W}$ on 162 changes in body mass and fat at mid-week (day 3) and at the end of the training week (day 5) 163 compared to baseline (day 1; before CM or W was ingested). Dietary records for each treatment 164 period were analysed using Comp-Eat Pro (version 5.7).

\section{Body mass and fat measurements}

167 Measurements of body mass (Seca 703, Vogel \& Halke, Germany) and body fat were made 4 168 times in total each week, before training ( 17:30) at days 1,3 and 5 and in the morning ( 8:30) 169 of day 6. Body fat was assessed via 4-site skinfold measurements (Harpenden, Baty Intl, West 170 Sussex, UK) and percentage of body fat was calculated using the equation of Jackson and 171 Pollock (1978).

174 Following a familiarization session, all subjects performed three judo-related performance tests 175 each time; before training on day 1 to obtain baseline measurements and again on the same time 
176 on day 5. The tests were performed at the dojo after warming-up and following body mass 177 measurements. On this order on all occasions, the athletes performed a counterbalanced 178 horizontal jump test, a timed push-ups test and a Special Judo Fitness Test (SJFT).

179 For the measurement of the horizontal jump distance, subjects performed a jump forwards two 180 times using a free countermovement jump protocol. The best of the two jumps was recorded. 181 Reliability of this test was previously assessed at ICC=0.85 (Papacosta et al., 2013).

182 Push-ups were performed in a prone position, by lowering and raising the body using the arms. 183 The athletes performed their maximal number of push-ups in a timed 30-s period. The number of 184 completed push-ups in $30 \mathrm{~s}$ was recorded as the score of the test. Reliability of this test in these 185 athletes was calculated as described previously (Papacosta et al., 2013) reaching a value of $186 \quad \mathrm{ICC}=0.79$.

187 The SJFT was conducted as described by Sterkowitz (1995). The test was conducted in series of 1883 bouts lasting $15 \mathrm{~s}, 30 \mathrm{~s}$ and $30 \mathrm{~s}$ interspersed by $10-\mathrm{s}$ intervals. During the test, the judoka 189 throws the two opponents as many times as possible using the ippon-seoi-nage technique. HR 190 was measured immediately at the end of the test and after 1 min using a HR monitor to calculate 191 the performance index as:

192 SJFT index $=($ HR immediately post + HR one minute post $) /$ total number of throws

193 A low SJFT index indicates better performance. Reliability of this test was previously assessed at 194 ICC=0.67 (Papacosta et al., 2013). 
DOMS was recorded on a visual analogue scale by rating the level of soreness on a scale of 1 (not sore) to 10 (extremely sore) for overall body soreness, soreness on front thigh muscles and soreness of upper body muscles (arms, chest, trapezoids). Subjects rated their subjective feeling of soreness while lightly palpating their muscles in a standing position. Mood state was assessed by the profile of mood state (POMS) questionnaire (McNair et al. 1971).

\section{Saliva collection and analysis}

Saliva samples were collected daily in the morning after an overnight fast at 07:00 within 10 min after waking up during all occasions (Figure 1). Subjects were instructed to swallow to empty their mouth before an unstimulated saliva sample was collected. Saliva collections were made with the subject seated, head leaning slightly forward with eyes open, and making minimal orofacial movement while passively dribbling into a sterile vial (Sterilin, Caerphily, UK). The collection time was 2 min at least or until an adequate volume of saliva $(\sim 1.5 \mathrm{ml})$ had been collected. Saliva was then stored in the same vials at $-30^{\circ} \mathrm{C}$ and were transported frozen to the Loughborough University laboratories for analysis. Concentrations of sC, sT and SIgA were determined in duplicate using commercially available ELISA kits (Salimetrics, PA, USA). Mean intra-assay coefficients of variation were $2.8 \%, 2.4 \%$ and $2.5 \%$ for $\mathrm{sC}$, sT and SIgA, respectively. Saliva volume was estimated by weighing the vial immediately after collection and assuming that saliva density was $1.00 \mathrm{~g} \cdot \mathrm{ml}^{-1}$ (Cole and Eastoe, 1988). Saliva flow rate was then calculated by dividing the total saliva volume collected in each sample (in ml) by the time taken to produce the sample (in $\mathrm{min}$ ). The SIgA secretion rate $\left(\mu \mathrm{g} \cdot \mathrm{min}^{-1}\right)$ was calculated by multiplying the absolute SIgA concentration $\left(\mu \mathrm{g} \cdot \mathrm{ml}^{-1}\right)$ by the saliva flow rate $\left(\mathrm{ml} \cdot \mathrm{min}^{-1}\right)$. 
221 Data was checked for normality, homogeneity of variance and sphericity before statistical 222 analysis. If Mauchly's test indicated that assumption of sphericity was violated the degrees of 223 freedom were corrected using Greenhouse-Geisser estimates. For statistical analysis a two-way 224 ANOVA for repeated measures (drink x time) with Bonferroni adjustments was used. The 95\% 225 confidence intervals (CI) for relative differences and size effects using Cohen's $r$ from simple 226 planned contrasts (Rosenthal et al., 2000) were calculated to confirm meaningful significant 227 differences. Mean nutrient intake and training volume in arbitrary units (AU) of each training 228 week were compared using dependent paired t-tests. Statistical significance was set at $\mathrm{p} \leq 0.05$. 229 All data are presented as mean \pm SD. Data was analysed using SPSS (SPSS v. 19.0; SPSS Inc, 230 Chicago, IL, USA).

232 Results

\section{Training load, ratings of perceived exertion and dietary intake}

234 Mean training load, RPE, training volume and time spend in each training zone did not present 235 significant differences between the two weeks ( $p>0.05$ ). Mean training load was $2805 \pm 190$ AU 236 and $2769 \pm 196$ AU during the week with the CM and W treatment, respectively. Mean RPE for 237 each training week was $16 \pm 1$. No significant differences $(\mathrm{p}>0.05)$ were found for dietary intake 238 between treatments. The mean 5-day energy intake was $2387 \pm 255 \mathrm{kcal}(\mathrm{CHO} 49.2 \pm 8.5 \%$, 239 protein $25.8 \pm 5.5 \%$, fat $25.0 \pm 6.3 \%$ ) during the $\mathrm{W}$ treatment, and $2575 \pm 315 \mathrm{kcal}(\mathrm{CHO} 51.7$ $240 \pm 8.9 \%$, protein $23.0 \pm 3.2 \%$, fat $25.3 \pm 7.4 \%$ ) during the CM treatment. 
243 Body mass decreased from baseline $(\mathrm{p}<0.001, r=0.55)$ on days 5 and 6 in $\mathrm{W}$ treatment and on 244 day 6 in $\mathrm{CM}$ treatment. Main effect for drink approached significance $(\mathrm{p}=0.08)$ with the decrease 245 in body weight by day 6 reaching $1.9 \%$ in the $\mathrm{W}$ treatment (CI -82 to $-191 \%$ ) and $1.1 \%$ in the 246 CM treatment (CI -48 to $-152 \%)$. Body fat increased by the end of each training week $(\mathrm{p}<0.001$, $247 r=0.64)$ by $\sim 1 \%$ in both the W (CI 30 to 197\%) and CM conditions (CI 61 to 206\%) with slighty 248 higher values during the CM week $(\mathrm{p}=0.003, r=0.75)$. (Table 2).

\section{Performance tests}

251 Performance in the horizontal jump did not change with the consumption of either beverage 252 ( $p>0.05$ ), even though mean jump performance was generally better during the CM condition $253(\mathrm{p}=0.05)$. Significant main effects of drink $(\mathrm{p}<0.001, r=0.71)$, time $(\mathrm{p}<0.001, r=0.64)$ and 254 interaction $(\mathrm{p}<0.001, r=0.74)$ showed that number of push-ups performed in $30-\mathrm{s}$ increased 255 significantly by the end of the training week in the CM but not in the $\mathrm{W}$ condition; performance 256 enhanced in all subjects by a mean of $14.6 \%$ in the CM condition (CI 63 to 136\%) and in 4 out of 25712 subjects by a mean of $2.2 \%$ in the W condition (CI -100 to $224 \%$ ). Mean number of throws in 258 the SJFT was generally higher during the CM condition $(\mathrm{p}<0.001)$, with no significant effects of 259 CM. Significant effects of drink $(\mathrm{p}=0.04, r=0.58)$, time $(\mathrm{p}=0.04, r=0.57)$ and interaction $260(\mathrm{p}=0.05, r=0.50)$ showed that SJFT performance index improved significantly by $6.8 \%$ after CM 261 consumption (CI 90 to 530\%) but not after W consumption (CI -67 to 265\%); performance 262 enhanced in 10 out of 12 subjects in the CM condition and in 5 out of 12 subjects in the W 263 condition (Table 3). 
266 Significant effects of drink $(\mathrm{p}<0.001, r=0.79)$, time $(\mathrm{p}<0.01, r=0.70)$ and interaction $(\mathrm{p}<0.001$, $267 r=0.77$ ) showed that general DOMS was lower throughout the week in the CM condition 268 compared with W (CI -45 to $-155 \%)$; muscle soreness rose from day 1 in both treatments but 269 kept increasing from mid-week to the end of the week in the W (CI 46 to $153 \%$ ) but not the CM 270 condition (CI -377 to 398$)$. DOMS was mainly located on upper body muscles ( $\mathrm{p}=0.002)$ with a 271 similar pattern of increase to general DOMS. DOMS of lower body increased from day 1 to the 272 end of the training week in the $\mathrm{W}$ condition but not in the CM condition ( $\mathrm{p}=0.04)$ (Table 4).

\section{Mood state}

275 Significant effects of drink $(\mathrm{p}<0.0001, r=0.85)$, time $(\mathrm{p}=0.007, r=0.72)$ and interaction $(\mathrm{p}<0.001$, $276 r=0.79$ ) showed that total mood disturbance scores were lower during the CM condition 277 compared with W (CI -33 to -165\%). By day 5, mood disturbance increased progressively from 278 day 1 during the W week (CI 54 to 146\%), whereas no significant changes were observed during 279 the $\mathrm{CM}$ week (CI -88 to $288 \%)$. Subscale of tension $(\mathrm{p}<0.01)$ was lower during the CM 280 compared with $\mathrm{W}$, without differences in subscales of vigour, aggression, confusion, fatigue and 281 depression between drinks ( $\mathrm{p}>0.05)$ (Table 4). 
286 Data for $\mathrm{sC}$, sT and sT/C ratio is shown on Figures $2 \mathrm{~A}, \mathrm{~B}$ and $\mathrm{C}$, respectively. A significant 287 effect of drink $(\mathrm{p}=0.02, r=0.68)$ and interaction $(\mathrm{p}<0.001, r=0.59)$ showed that mean $\mathrm{sC}$ 288 concentrations were significantly lower during the week with the CM condition (CI -18 to $289182 \%)$ without significant differences across time $(\mathrm{p}>0.05)$. Concentrations of sT were similar 290 across time and between the two treatments $(\mathrm{p}>0.05)$. Significant main effects of time $(\mathrm{p}=0.03$, $291 r=0.44)$ and interaction $(\mathrm{p}=0.02, r=0.67)$ showed that mean sT/C ratio increased significantly

292 from baseline in the CM treatment (day 2: CI 5 to 195\%; day 4: CI 1 to 249\%) with a tendency 293 for higher values during the CM condition compared with $\mathrm{W}$ ( $\mathrm{p}=0.07, r=0.48$; CI -9 to 209\%).

$<<$ Figure 2 about here $>>$

295

\section{Saliva SIgA}

296 Data for SIgA absolute concentrations and secretion rate is shown in Figures 3 A and B, 297 respectively. Although mean SIgA absolute concentrations increased in the morning of the 298 competition day from the first days of the week in the $\mathrm{W}$ condition $(\mathrm{p}=0.004, r=0.26)$, no 299 significant effect of drink or interaction was found $(\mathrm{p}>0.05)$.

300 A significant effect of time showed that mean SIgA secretion rate increased towards the end of 301 the week $(\mathrm{p}=0.02, r=0.81)$, in a similar manner in both conditions $(\mathrm{p}>0.05)$.

\section{Saliva flow rate}

304 A significant main effect of drink $(\mathrm{p}=0.008, r=0.70)$ and interaction $(\mathrm{p}<0.001, r=0.72)$ showed 305 that mean saliva flow rate was significantly higher during the week of the CM condition 

compared with W (CI $86-111 \%)$, without significant changes across time ( $>>0.05)$. Data is 307 shown in Figure 3 C. 


\section{Discussion}

311 This study showed that post-exercise chocolate milk consumption during 5 days of intensive

312 judo training was favourable for enhancing several aspects of recovery from intensive judo

313 training, without affecting intentional weight loss. Post-exercise CM consumption was associated

314 with lower $\mathrm{sC}$ responses and higher saliva flow, attenuated muscle soreness ratings, ameliorated

315 mood disturbance and enhanced judo-specific performance.

316 In this study, post-exercise CM consumption improved timed push-ups and judo-specific

317 performance by the end of the week, without changes in countermovement jump. The findings of

318 our study agree with some (Karp et al. 2006; Cockburn et al. 2008; Thomas et al. 2009;

319 Ferguson-Stegall et al. 2011; Lunn et al. 2012) but not all studies (Pritchett et al., 2009; Gilson et

320 al. 2010; Spaccarotella and Andzel 2011). The majority of previous investigations assessed the

321 effects of CM during laboratory-based standardized tests, whereas the present study assessed the

322 effects of $\mathrm{CM}$ in an applied sport setting. Our previous study in these athletes showed that

323 responses of $\mathrm{sC}$, SIgA, saliva flow rate, muscle soreness, mood state and judo-related

324 performance can serve as markers of training and recovery in judo (Papacosta et al. 2013);

325 therefore the present study assessed the effects of CM during recovery on judo-related, field 326 performance.

327 Morning $\mathrm{SC}$ concentrations were lower in the week of the CM treatment compared with W, 328 which may indicate that accumulated stress of the consecutive intense training sessions was 329 lower when CM was consumed. Similarly, mood was not disturbed when CM was consumed 330 after training. Deterioration of physical performance, elevated cortisol responses and disturbance 331 of mood state are all considered as markers of overreaching and recovery (Meeusen et al. 2013). 
$332 \mathrm{CHO}$ supplementation during intensified exercise/training has been shown to maintain physical 333 performance and mood (Achten et al. 2004; Halson et al. 2004). Therefore we suggest that the 334 post-exercise CM consumption aided the recovery from exercise and attenuated the symptoms of 335 overreaching during a short-term period of intense judo training, possibly due to enhanced 336 energy and CHO availability. SIgA did not exhibit differences between conditions; however, the 337 duration of the intensive training period may have been too short for any changes in SIgA levels.

338 Attenuation of muscle soreness ratings during the week with $\mathrm{CM}$ consumption was observed in 339 this study. These results agree with the findings of Cockburn et al. (2010) who reported that CM 340 consumption after muscle-damaging exercise attenuated the increases in DOMS, enhanced 341 muscle-related performance and attenuated the rise in CK responses. Similar investigations 342 showed attenuated rises in CK after the consumption of CM during recovery (Wojcik et al. 2001;

343 Cockburn et al. 2008; Pritchett et al. 2009; Gilson et al. 2010). It has been previously suggested 344 that the protein content in the CM was associated with higher muscle amino-acid uptake and 345 increased muscle protein synthesis (Wilkinson et al. 2007) as well as increased activation status 346 of signalling proteins associated with protein synthesis and attenuation of markers of muscle 347 protein degradation (Ferguson-Stegall et al. 2011; Lunn et al. 2012). In our study, the 348 combination of lower sensation of muscle soreness and enhancement in functional tests with 349 post-exercise CM consumption could be attributed to a lower degree of muscle tissue disruption 350 with the CM.

351 One of the aims of this study was to observe whether consuming a milk-based CHO-protein 352 recovery beverage could affect pre-competition weight loss in judo. Typically, judo athletes do 353 not tend to consume $\mathrm{CHO}$ in the week preceding a competition, as it could possibly interfere 354 with their weight loss practices. In our study, body mass decreased by the morning of the 
355 competition day in both conditions, thus by $1.9 \%$ in the $\mathrm{W}$ condition and $1.1 \%$ in the $\mathrm{CM}$ 356 condition. Although not reaching statistical significance, body weight was relatively maintained

357 throughout the CM week, whereas it was reduced progressively in the $\mathrm{W}$ condition, which could 358 be in accordance with the enhanced mood state that was evident in the week with CM 359 consumption. This fact could indicate two things: (a) that the higher energy content in the CM 360 affected the usual weight loss practice of the judo athletes, as seen on W week (observation 361 week), and making it more difficult to "make weight" or (b) the reduction in body weight of 362 these athletes was actually the effect of mild dehydration. Although no urine osmolality 363 measurements were made, saliva flow rate was higher during the CM week compared with the W 364 week. This could indicate that CM may have been associated with enhanced hydration in these 365 athletes, as decreased rates of saliva flow were reported in dehydrated subjects (Fortes et al. 366 2012). Previous studies have shown that fluid milk consumption post-exercise was more 367 effective in restoring sweat losses compared with W after exercise-induced mild dehydration 368 (Shirreffs et al. 2007), whereas in already exercise/heat-induced dehydrated subjects milk was 369 effective for maintaining positive net fluid balance during recovery (Watson et al. 2008). This 370 could explain the difference in weight loss between the two beverages, indicating that athletes 371 possibly had higher fluid retention during recovery and were in positive net fluid balance with 372 the CM. Therefore, it appears more probable that the decrease in weight loss in these athletes 373 was actually a result of mild dehydration. The findings indicate that CM consumption post374 exercise probably has no meaningful effect on the athletes' weight loss practices; on the contrary 375 the beneficial effects of the CM for enhancing recovery may be more important for effective 376 competition performance than any possible consequence on weight loss. 
377 Limitations of this study were the lack of a randomised, double-blind, crossover design with

378 equicaloric placebo. Due to the nature of the beverages, it was impossible to blind the treatment

379 to the researchers and participants. The lack of equicaloric placebo in this study was chosen as to

380 comply with the usual nutritional practices of judo athletes preceding competition; however,

381 future investigations may assess the effects of $\mathrm{CM}$ versus a same equicaloric, flavoured and

382 coloured beverage. The reason for not choosing a crossover design was to eliminate the bias of

383 subjects regarding practices for weight loss. Athletes were requested to follow their usual

384 practices for "making weight" in the first week, and follow these practices during the CM week.

385 Should CM had been given to some athletes on the first week and observe that it interfered with

386 their required weight loss it is possible that on the second week these athletes would try harder to

387 lose weight by further reducing energy consumption. Even though the athletes were instructed to

388 follow the same diet on both weeks and while care was taken as to try to control for all food and

389 drink intake via food diaries, athletes had all their meals at their own space without supervision.

390 However, it should be noted that this was a field study involving national elite athletes during

391 "real-life" training situations; therefore the main objective of athletes and coaches was to

392 enhance performance and perform better at the upcoming competition. Hence, a crossover design

393 was not a safe choice for this cohort of athletes because of the risk that energy consumption

394 would not have been the same between conditions and consequently the effects of CM on weight

395 loss would not have been reliable.

396 In conclusion, this study suggests that CM can successfully serve as a recovery beverage during

397 periods of intensive judo training as it can have beneficial effects on several aspects of recovery,

398 without meaningful effects on pre-competition intentional weight loss. This study identified that

399 the consumption of CM compared with W during 5 days of intensive judo training was 
400 associated with lower $\mathrm{sC}$ responses, limited the disturbances in mood, attenuated ratings of 401 muscle soreness and enhanced judo-related performance, possibly attributed to the higher caloric 402 content.

403

404 Acknowledgements

405 The authors thank the National Judo Federation and the judo coaches for their support and 406 especially Mr. Phoivos Christou, Mr. Christos Christodoulides and Mr. Sasa Jankovic for their 407 technical help during the study. Chocolate milks were purchased from Lanitis Dairy, Ltd. This 408 study was financially supported by A.G. Levendis Foundation.

409 
411 Achten, J., Halson, S. L., Moseley, L., Rayson, M. P., Casey, A. and Jeukendrup, A. E. 2004. Higher

412 dietary carbohydrate content during intensified running training results in better maintenance of

413 performance and mood state. J. Appl. Physiol. (1985), 96, 1331-1340.

414 Artioli, G. G., Gualano, B., Franchini, E., Scagliusi, F. B., Takesian, M., Fuchs, M. and Lancha, A. H., Jr. 415 2010. Prevalence, magnitude, and methods of rapid weight loss among judo competitors. Med. Sci.

416 Sports. Exerc. 42, 436-442.

417 Borg, G. A. 1982. Psychophysical bases of perceived exertion. Med. Sci. Sports. Exerc. 14, 377-381.

418 Cockburn, E., Hayes, P. R., French, D. N., Stevenson, E. and St Clair Gibson, A. 2008. Acute milk-based 419 protein-CHO supplementation attenuates exercise-induced muscle damage. Appl. Physiol. Nutr. Metab. $420 \quad 33,775-783$

421 Cockburn, E., Stevenson, E., Hayes, P. R., Robson-Ansley, P. and Howatson, G. 2010. Effect of milk422 based carbohydrate-protein supplement timing on the attenuation of exercise-induced muscle damage. 423 Appl. Physiol. Nutr. Metab. 35, 270-277.

424 Cole, A. S. and Eastoe, J. E. 1988. Biochemistry and Oral Biology, London, Wright.

425 Cooke, C. B. 2009. Maximal oxygen uptake, economy and efficiency. In: Eston, R. a. R., T. (ed.) 426 Kinanthropometry and Exercise Physiology laboratory manual: Tests, procedures and data. 3rd ed. 427 London: Routledge.

428 Ferguson-Stegall, L., McCleave, E. L., Ding, Z., Doerner, P. G., 3rd, Wang, B., Liao, Y. H., Kammer, L., 429 Liu, Y., Hwang, J., Dessard, B. M. and Ivy, J. L. 2011. Postexercise carbohydrate-protein 
supplementation improves subsequent exercise performance and intracellular signaling for protein synthesis. J. Strength. Cond. Res. 25, 1210-1224.

Fortes, M. B., Diment, B. C., Di Felice, U. and Walsh, N. P. 2012. Dehydration decreases saliva antimicrobial proteins important for mucosal immunity. Appl. Physiol. Nutr. Metab. 37, 850-859.

Foster, C., Florhaug, J. A., Franklin, J., Gottschall, L., Hrovatin, L. A., Parker, S., Doleshal, P. and Dodge, C. 2001. A new approach to monitoring exercise training. J. Strength. Cond. Res. 15, 109-115.

Gilson, F. S., Saunders, M. J., Moran, C. W., Moore, R. W., Womack, C. J. and Kent, M. K. 2010. Effects of chocolate milk consumption on markers of muscle recovery following soccer training: a randomized cross-over study. J. Int. Soc. Sports. Nutr. 7, 19.

Halson, S. L., Lancaster, G. I., Achten, J., Gleeson, M. and Jeukendrup, A. E. 2004. Effects of carbohydrate supplementation on performance and carbohydrate oxidation after intensified cycling training. J. Appl. Physiol. (1985), 97, 1245-1253.

Jackson, A. S. and Pollock, M. L. 1978. Generalized equations for predicting body density of men. Br. J. Nutr. 40, 497-504.

Karp, J. R., Johnston, J. D., Tecklenburg, S., Mickleborough, T. D., Fly, A. D. and Stager, J. M. 2006. Chocolate milk as a post-exercise recovery aid. Int. J. Sport. Nutr. Exerc. Metab. 16, 78-91.

Lunn, W. R., Pasiakos, S. M., Colletto, M. R., Karfonta, K. E., Carbone, J. W., Anderson, J. M. and Rodriguez, N. R. 2012. Chocolate milk and endurance exercise recovery: protein balance, glycogen, and performance. Med. Sci. Sports. Exerc. 44, 682-691.

McNair, D. M., Lorr, M. and Droppleman, L. F. 1971. Manual for the Profile of Mood States. , San Diego, CA. 
451 Meeusen, R., Duclos, M., Foster, C., Fry, A., Gleeson, M., Nieman, D., Raglin, J., Rietjens, G.,

452 Steinacker, J. and Urhausen, A. 2013. Prevention, diagnosis, and treatment of the overtraining syndrome:

453 joint consensus statement of the European College of Sport Science and the American College of Sports

454 Medicine. Med. Sci. Sports. Exerc. 45, 186-205.

455 Papacosta, E., Gleeson, M., and Nassis, G.P. 2013. Salivary hormones, IgA, and performance

456 during intense training and tapering in judo athletes. J. Strength. Cond. Res. 27, 2569-2580,

457 Pritchett, K., Bishop, P., Pritchett, R., Green, M. and Katica, C. 2009. Acute effects of chocolate

458 milk and a commercial recovery beverage on postexercise recovery indices and endurance

459 cycling performance. Appl. Physiol. Nutr. Metab. 34, 1017-1022.

460 Rosenthal, R., Rosnow R.L. and Rubin, D.B. 2000. Contrasts and effect sizes in behavioural

461 research: a correlational approach. Cambridge: Cambridge University Press

462 Shirreffs, S. M., Watson, P. and Maughan, R. J. 2007. Milk as an effective post-exercise

463 rehydration drink. Br. J. Nutr. 98, 173-180.

464 Spaccarotella, K. J. and Andzel, W. D. 2011. The effects of low fat chocolate milk on postexercise

465 recovery in collegiate athletes. J. Strength. Cond. Res. 25, 3456-3460.

466 Sterkowitz, S. 1995. Special Judo Fitness Test. Antropomotoryka, 12/13, 29-44.

467 Thomas, K., Morris, P. and Stevenson, E. 2009. Improved endurance capacity following chocolate milk

468 consumption compared with 2 commercially available sport drinks. Appl. Physiol. Nutr. Metab. 34, 78-

$469 \quad 82$. 
470 Watson, P., Love, T. D., Maughan, R. J. and Shirreffs, S. M. 2008. A comparison of the effects of milk

471 and a carbohydrate-electrolyte drink on the restoration of fluid balance and exercise capacity in a hot,

472 humid environment. Eur. J. Appl. Physiol. 104, 633-642.

473 Wilkinson, S. B., Tarnopolsky, M. A., Macdonald, M. J., Macdonald, J. R., Armstrong, D. and Phillips, S.

474 M. 2007. Consumption of fluid skim milk promotes greater muscle protein accretion after resistance

475 exercise than does consumption of an isonitrogenous and isoenergetic soy-protein beverage. Am. J. Clin.

$476 \quad$ Nutr. 85, 1031-1040.

477 Walsh, N. P., Gleeson, M., Shephard, R. J., Woods, J. A., Bishop, N. C., Fleshner, M., Green, C.,

478 Pedersen, B. K., Hoffman-Goetz, L., Rogers, C. J., Northoff, H., Abbasi, A. and Simon, P. 2011.

479 Position statement. Part one: Immune function and exercise. Exerc. Immunol. Rev. 17, 6-63.

480 Wojcik, J. R., Walber-Rankin, J., Smith, L. L. and Gwazdauskas, F. C. 2001. Comparison of carbohydrate 481 and milk-based beverages on muscle damage and glycogen following exercise. Int. J. Sport. Nutr. Exerc.

482 Metab. 11, 406-419. 
Table 1. Ingredients of the chocolate milk beverage

\begin{tabular}{|lr|}
\hline Energy $\left(\mathrm{kcal} \cdot \mathrm{L}^{-1}\right)$ & 870.0 \\
Carbohydrates $\left(\mathrm{g} \cdot \mathrm{L}^{-1}\right)$ & 107.0 \\
of which sugars & 105.0 \\
Protein $\left(\mathrm{g} \cdot \mathrm{L}^{-1}\right)$ & 35.0 \\
Fat $\left(\mathrm{g} \cdot \mathrm{L}^{-1}\right)$ & 33.0 \\
\multicolumn{1}{c}{ of which saturates } & 19.0 \\
Sodium $\left(\mathrm{g} \cdot \mathrm{L}^{-1}\right)$ & 0.7 \\
Calcium $\left(\mathrm{g} \cdot \mathrm{L}^{-1}\right)$ & 0.9 \\
Phosphorus $\left(\mathrm{g} \cdot \mathrm{L}^{-1}\right)$ & 1.3 \\
Vitamin $\mathrm{B} 2\left(\mathrm{mg} \cdot \mathrm{L}^{-1}\right)$ & 1.5 \\
Cocoa $\left(\mathrm{g} \cdot \mathrm{L}^{-1}\right)$ & 13.5 \\
\hline
\end{tabular}

values supplied by manufacturer

Table 2. Changes in body mass and body fat during the water (W) and chocolate milk (CM) treatment (Mean \pm SD).

\begin{tabular}{|c|c|c|c|c|c|c|c|c|c|c|c|c|c|}
\hline & & & $\mathbf{A Y}$ & & & $\mathbf{Y Y}$ & & & A & & & $\mathbf{A Y}$ & \\
\hline \multirow{2}{*}{ Body mass (kg) } & W & 78.2 & \pm & 7.4 & 77.8 & \pm & 7.5 & 77.4 & \pm & $7.5^{*}$ & 76.7 & \pm & $7.3 * \S$ \\
\hline & $\mathrm{CM}$ & 78.3 & \pm & 8.0 & 78.3 & \pm & 8.0 & 78.4 & \pm & 8.1 & 77.5 & \pm & $8.0 * \S$ \\
\hline \multirow{2}{*}{ Body fat (\%) } & $\mathrm{W}$ & 12.4 & \pm & 3.8 & 12.6 & \pm & 3.5 & 13.6 & \pm & $4.5^{*} \S$ & 13.0 & \pm & 4.1 \\
\hline & $\mathrm{CM}$ & 13.3 & \pm & 4.8 & 13.3 & \pm & 3.4 & 14.1 & \pm & $3.1 * \S$ & 13.7 & \pm & 3.8 \\
\hline
\end{tabular}

491 Data are mean $\pm \mathrm{SD}$; * indicates significantly different $(\mathrm{p}<0.05)$ from day 1 ; $\S$ indicates significantly different $492 \quad(\mathrm{p}<0.05)$ from day 3. 
496 Table 3. Performance tests at the beginning (DAY 1) and end (DAY 5) of training weeks during the water (W) and

497 chocolate milk $(\mathrm{CM})$ treatment $($ Mean $\pm \mathrm{SD})$.

\begin{tabular}{llllllll}
\hline Performance test & & \multicolumn{1}{c}{ DAY 1 } & \multicolumn{2}{c}{ DAY 5 } \\
\hline \multirow{2}{*}{ Horizontal jump (m) } & W & 2.32 & \pm 0.16 & 2.36 & \pm & 0.21 \\
& CM & 2.41 & \pm & $0.17 \#$ & 2.43 & \pm & $0.17 \#$ \\
\hline \multirow{2}{*}{ Push-ups in 30 s (no.) } & W & 45 & \pm 7 & 46 & \pm & 6 \\
& CM & 48 & \pm & 55 & \pm & $6^{* \#}$ \\
\hline \multirow{2}{*}{ Special Judo Fitness Test (throws) } & W & 25 & \pm 3 & 25 & \pm & 3 \\
& CM & 27 & $\pm 2 \#$ & 28 & \pm & $2 \#$ \\
\hline \multirow{2}{*}{ Special Judo Fitness Test (index) } & W & 14.2 & \pm 1.6 & 13.7 & \pm & 1.2 \\
& CM & 13.3 & \pm 2.1 & 12.4 & \pm & $1.1^{*} \#$ \\
\hline
\end{tabular}

498

Data are mean $\pm \mathrm{SD} ; *$ indicates significantly different $(\mathrm{p}<0.05)$ from Pre; \# indicates significantly different $499 \quad(\mathrm{p}<0.05)$ than $\mathrm{W}$.

500

501 
Table 4. Changes in muscle soreness and mood disturbance during the weeks with water (W) and chocolate milk

(CM) treatment (Mean \pm SD).

\begin{tabular}{|c|c|c|c|c|c|c|c|c|c|c|}
\hline \multirow{3}{*}{ General muscle soreness } & \multirow[b]{2}{*}{$\mathrm{W}$} & \multicolumn{3}{|c|}{ DAY 1} & \multicolumn{3}{|c|}{ DAY 3} & \multicolumn{3}{|c|}{ DAY 5} \\
\hline & & 1.5 & \pm & 0.7 & 3.2 & \pm & $1.6 *$ & 4.5 & \pm & $1.8 * \S$ \\
\hline & $\mathrm{CM}$ & 1.6 & \pm & 0.8 & 2.4 & \pm & $1.0 * \#$ & 2.5 & \pm & $1.0 * \#$ \\
\hline \multirow{2}{*}{ Front thigh soreness } & $\mathrm{W}$ & 1.4 & \pm & 0.7 & 2.2 & \pm & 1.6 & 3.4 & \pm & $1.6 *$ \\
\hline & $\mathrm{CM}$ & 1.3 & \pm & 0.6 & 2.2 & \pm & 0.8 & 2.4 & \pm & $1.1 \#$ \\
\hline \multirow{2}{*}{ Upper body soreness } & $\mathrm{W}$ & 1.2 & \pm & 0.4 & 2.8 & \pm & $1.6 *$ & 3.8 & \pm & $1.6 * \S$ \\
\hline & $\mathrm{CM}$ & 1.5 & \pm & 0.8 & 2.2 & \pm & $0.8 * \#$ & 2.3 & \pm & $1.1 * \#$ \\
\hline \multirow{2}{*}{ Total mood disturbance } & $\mathrm{W}$ & -6.0 & \pm & 5.1 & 1.4 & \pm & $7.3 *$ & 4.8 & \pm & $6.1 * \S$ \\
\hline & $\mathrm{CM}$ & -4.3 & \pm & 5.2 & -1.6 & \pm & 5.3 & -3.4 & \pm & $6.0 \#$ \\
\hline \multirow{2}{*}{ Vigour } & $\mathrm{W}$ & 13.9 & \pm & 3.7 & 11.1 & \pm & 4.1 & 9.6 & \pm & 3.8 \\
\hline & $\mathrm{CM}$ & 10.7 & \pm & 3 & 11.1 & \pm & 3.7 & 11.1 & \pm & 2.9 \\
\hline \multirow{2}{*}{ Tension } & $\mathrm{W}$ & 2.2 & \pm & 2 & 3.6 & \pm & 2.8 & 4.7 & \pm & 3.7 \\
\hline & $\mathrm{CM}$ & 2.0 & \pm & 1.8 & 2.6 & \pm & 2.9 & 2.6 & \pm & $2.6 \#$ \\
\hline \multirow{2}{*}{ Depression } & $\mathrm{W}$ & 0.2 & \pm & 0.4 & 1.0 & \pm & 1.2 & 0.7 & \pm & 1.2 \\
\hline & $\mathrm{CM}$ & 0.3 & \pm & 0.7 & 0.1 & \pm & 0.3 & 0.1 & \pm & 0.3 \\
\hline \multirow{2}{*}{ Aggression } & $\mathrm{W}$ & 1.6 & \pm & 1 & 2.3 & \pm & 2.4 & 2.3 & \pm & 1.6 \\
\hline & $\mathrm{CM}$ & 2.0 & \pm & 1.2 & 1.8 & \pm & 2.2 & 1.9 & \pm & 1.9 \\
\hline \multirow{2}{*}{ Fatigue } & $\mathrm{W}$ & 3.7 & \pm & 2.2 & 5.2 & \pm & 1.9 & 6.3 & \pm & 3.8 \\
\hline & $\mathrm{CM}$ & 4.0 & \pm & 3 & 5.1 & \pm & 2.1 & 3.8 & \pm & 3.2 \\
\hline \multirow{2}{*}{ Confusion } & $\mathrm{W}$ & 0.3 & \pm & 0.5 & 0.4 & \pm & 0.7 & 0.4 & \pm & 0.5 \\
\hline & $\mathrm{CM}$ & 0.6 & \pm & 1.1 & 0.3 & \pm & 0.7 & 0.2 & \pm & 0.4 \\
\hline
\end{tabular}

* indicates significantly different $(\mathrm{p}<0.05)$ from day $1 ; \S$ indicates significantly different $(\mathrm{p}<0.05)$ from day 3 ; \# 505 indicates significantly different $(\mathrm{p}<0.05)$ than $\mathrm{W}$ 
507 Figure 1. Schematic representation of experimental study design. BM indicates body mass and

508 fat measurements; Q indicates questionnaire assessments; s indicates saliva collection.

509 Figure 2. Mean ( \pm SD) concentrations of [A] salivary cortisol, [B] salivary testosterone and [C] salivary T/C 510 ratio during the weeks with water (grey columns) and chocolate milk (black columns) conditions.

511 a indicates significantly different $(\mathrm{p}<0.05)$ from day 1 ; \# indicates significantly different $(\mathrm{p}<0.05)$ than water.

512

513 Figure 3. Mean ( \pm SD) concentrations of [A] SIgA absolute concentrations, [B] SIgA secretion rate and [C] 514 saliva flow rate during the weeks with water (grey columns) and chocolate milk (black columns) conditions. $₫$ 515 indicates significantly different $(\mathrm{p}<0.05)$ from day $1 ; \dagger$ indicates significantly different $(\mathrm{p}<0.05)$ from day 2 ; \# 516 indicates significantly different $(\mathrm{p}<0.05)$ than water. 
Figure 1

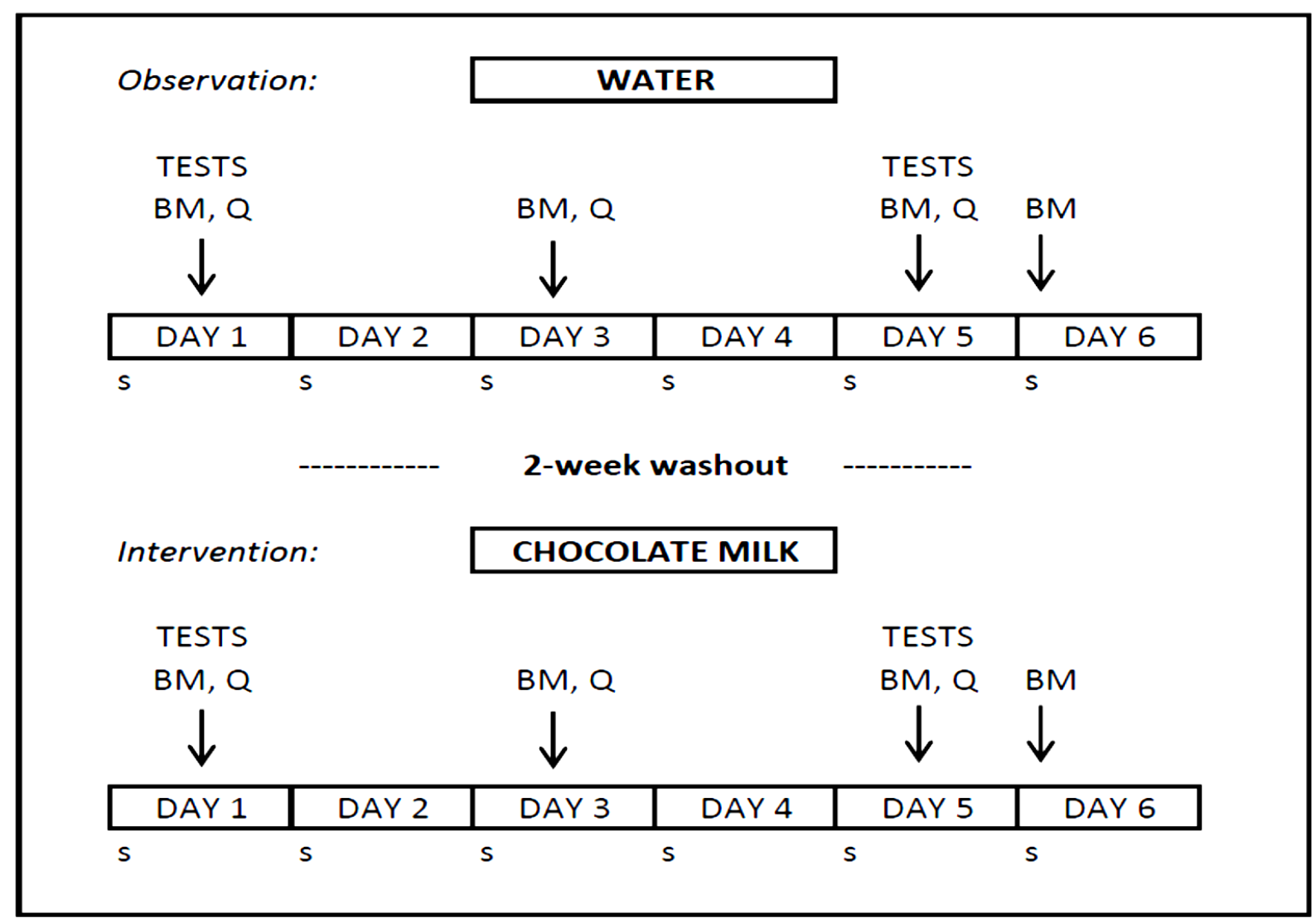

521 
Figure 2

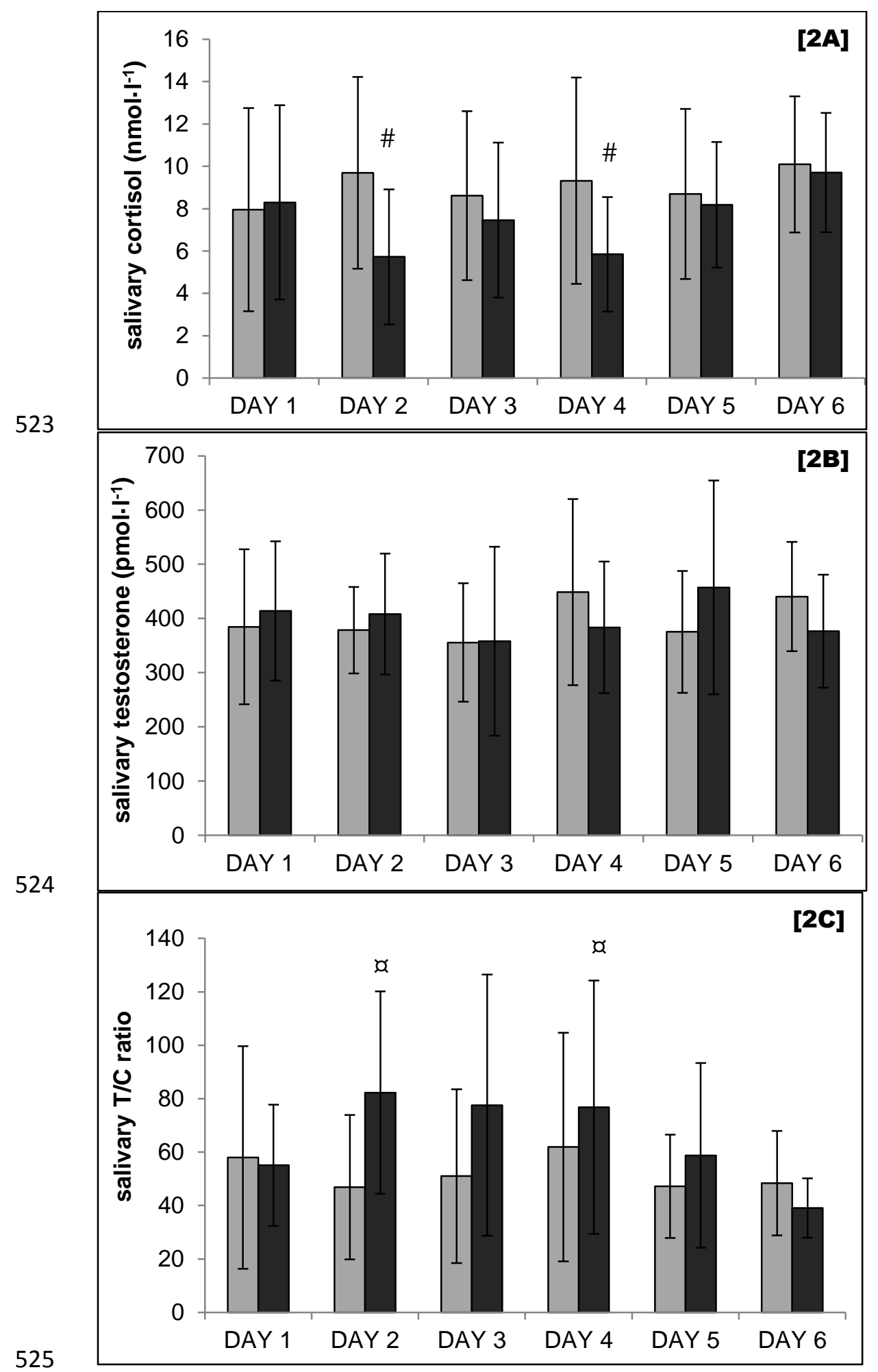


Figure 3

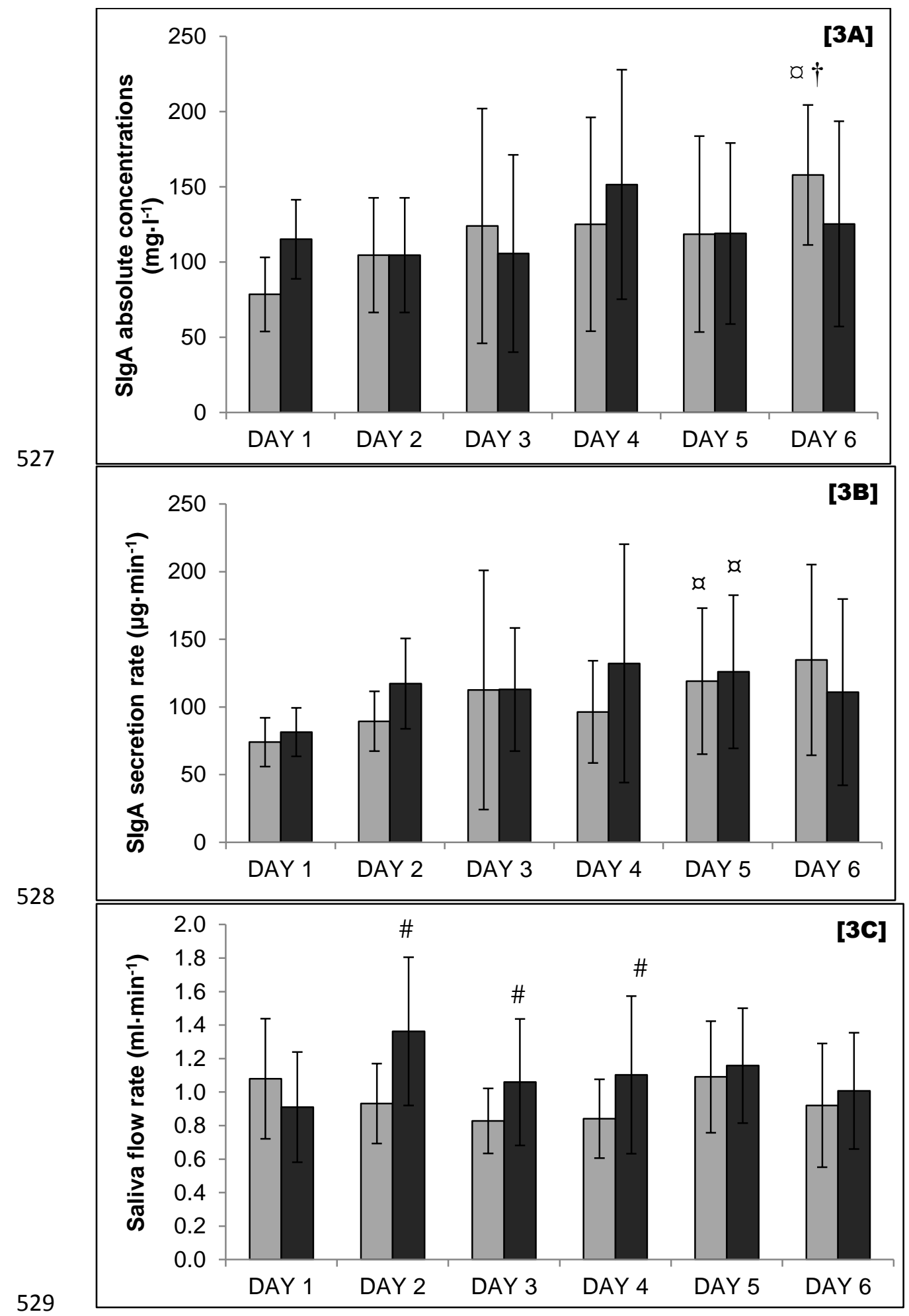

